\section{Revista Brasileira de Administração Científica}

Brazilian Journal of Scientific Administration

Out a Dez 2020 - v.11 - n.4

\title{
Educação a distância para a qualificação do servidor público: mapeamento da base SPELL (2015-2019)
}

A Administração Pública contemporânea deve ser reconhecida e analisada de maneira sistêmica, compreendendo as ações e serviços públicos como resultados da qualificação de seus servidores, que pode ser promovida mediante o uso de diversas modalidades de ensino, dentre as quais se destaca a educação a distância (EAD). Através da EAD, é possível promover a profissionalização dos servidores e serviço público, possibilitando o aprendizado coletivo e transformando os órgãos da Administração Pública em organizações que aprendem. Este estudo tem a finalidade de contextualizar e identificar, através de pesquisa bibliométrica, as produções científicas nacionais relacionadas à educação a distância na Administração Pública a partir da base de dados Scientific Periodicals Electronic Library (SPELL), através de abordagem quali-quantitativa. O artigo encontra-se dividido em cinco partes, iniciando-se pela introdução; o tópico a seguir contempla o os procedimentos adotados para a coleta das informações necessárias ao estudo; em sequência, expõe-se o referencial teórico, contextualizando as temáticas abordadas e analisando os dados coletados. Por fim, apresentam-se as considerações finais, seguidas pelas referências utilizadas para seu desdobramento. Os resultados apontam para um número reduzido de publiçções acerca deste tema e em conformidade com os critérios metodológicos estabelecidos, evidenciando um campo notável para a realização deste e de futuros estudos.

Palavras-chave: Aprendizagem organizacional pública; Educação a distância; Qualificação do servidor público.

\section{Distance education to qualify public server: mapping the SPELL base (2015-2019)}

\begin{abstract}
Contemporary Public Administration must be recognized and analyzed in a systemic manner, understanding public actions and services as the results of the qualification of its employees, which can be promoted through the use of various teaching modalities, among which distance education stands out. Through distance education, it is possible to promote the professionalization of civil servants and public service, enabling collective learning and transforming Public Administration bodies into learning organizations. This study aims to contextualize and identify, through bibliometric research, the national scientific productions related to distance education in Public Administration from the Scientific Periodicals Electronic Library (SPELL) database, through a quali-quantitative approach. The article is divided into five parts, starting with the introduction; the following topic includes the procedures adopted to collect the information necessary for the study; in sequence, the theoretical framework is exposed, contextualizing the themes addressed and analyzing the data collected. Finally, the final considerations are presented, followed by the references used for their unfolding. The results point to a reduced number of publications on this topic and in accordance with the established methodological criteria, showing a remarkable field for the realization of this and future studies.
\end{abstract}

Keywords: Public organizational learning; Distance education; Qualification of public servants.

Topic: Recursos Humanos

Reviewed anonymously in the process of blind peer.
Received: 02/10/2020

Approved: $\mathbf{2 1 / 1 2 / 2 0 2 0}$
Tassia Tabille Steglich (iD)

Universidade Federal de Santa Maria, Brasil

http://lattes.cnpq.br/3960903989403043

http://orcid.org/0000-0002-9692-7753

tassiatsteglich@gmail.com

Eric Charles Henri Dorion (iD

Universidade Federal de Santa Maria, Brasi

http://lattes.cnpq.br/8616796657243433

http://orcid.org/0000-0002-3472-3835

tassiatsteglich@gmail.com
Referencing this:

STEGLICH, T. T.; DORION, E. C. H.. Educação a distância para a qualificação do servidor público: mapeamento da base SPELL (20152019). Revista Brasileira de Administração Científica, v.11, n.4, p.4456, 2020. DOI: http://doi.org/10.6008/CBPC2179-684X.2020.004.0004

DOI: 10.6008/CBPC2179-684X.2020.004.0004 


\section{INTRODUÇÃO}

O aprendizado constante na Administração Pública ainda é uma discussão recente em estudos administrativos e produções acadêmicas, em virtude de séculos fundamentados no patrimonialismo e na burocracia, embaraçando e mecanizando processos de gestão pública. Mais recentemente, passou-se a refletir sobre a relevância da qualificação do servidor público, considerando a sua atuação profissional como uma premissa da qualidade do serviço público em um mundo cada vez mais globalizado, tecnológico e imediatista (BERTOLIN et al., 2013; TEPERINO et al., 2006). Deste modo, o presente artigo busca conduzir à resposta do seguinte questionamento: Qual é o estado da arte das produções científicas indexadas na base de dados SPELL acerca da educação a distância como instrumento de qualificação do servidor público?.

Desde a década de 90, o termo learning organization passou a definir as organizações que possuíssem uma visão sistêmica, ou seja, capazes de integrar todos os setores e processos para a tomada de decisões estratégicas (SENGE, 2013). Na Administração Pública, apesar dos rompimentos de paradigmas transcorridos nas últimas décadas, o pensamento integrado encontra-se a passos lentos, junto às questões que envolvem a qualificação profissional do servidor público. Com a evolução das tecnologias, a educação a distância (EAD) tornou-se cada vez mais corriqueira (PONTES et al., 2017), podendo ser amplamente utilizada na Administração Pública como instrumento de promoção da aprendizagem organizacional.

Considerando a necessidade cada vez mais constante de se promover serviços públicos eficazes e eficientes, no intuito de atender às demandas de uma sociedade gradativamente mais exigente e melhor informada acerca das ações públicas, depreende-se a relevância da qualificação dos servidores e, consequentemente, a transformação dos órgãos da Administração Pública em organizações que aprendem (LUCCA et al., 2018; MCCURDY, 2011). Nesta seara, destaca-se a possibilidade de utilização das tecnologias, cada vez mais presentes na sociedade e que permitem o compartilhamento de informações e conhecimento, transpassando distâncias geográficas e diferenças organizacionais.

Deste modo, o estudo tem a finalidade de contextualizar e identificar, através de pesquisa bibliométrica, as produções científicas nacionais relacionadas à educação a distância na Administração Pública a partir da base de dados SPELL, através de abordagem quali-quantitativa. Para tanto, delimitaramse como objetivos específicos: a) quantificar, através da busca por termos-chave, a produção científica nacional na base de dados mencionada; b) identificar os períodos de maior produção acerca das temáticas e buscar suas justificativas e c) identificar e analisar as produções com maior aderência ao tema pretendido no período de 2015-2019. Os resultados apontam para um número reduzido de publicações acerca deste tema e em conformidade com os critérios metodológicos estabelecidos, evidenciando um campo notável para a realização do presente estudo.

O artigo encontra-se dividido em cinco partes, além da introdução. O tópico a seguir contempla o os procedimentos adotados para a coleta das informações necessárias ao estudo; em sequência, expõe-se o referencial teórico, contextualizando as temáticas abordadas e analisando os dados coletados. Por fim, apresentam-se as considerações finais, seguidas pelas referências utilizadas para seu desdobramento. 


\section{METODOLOGIA}

O presente estudo se configura em uma pesquisa quali-quantitativa de cunho exploratório. A abordagem qualitativa é definida por Minayo (2002) como o estudo da realidade através da proposição de significados, "o que corresponde a um espaço mais profundo das relações, dos processos e dos fenômenos", ou seja, não podem ser reduzidos a números quantificáveis e variáveis estatísticas. Em contrapartida, depreende-se o caráter quantitativo deste estudo em virtude da utilização de técnica quantitativa (bibliometria), sendo possível a elaboração de um panorama sistemático e quantificável sobre o que já foi elaborado acerca da temática pretendida (ARAÚJO, 2006). A característica exploratória da pesquisa, por sua vez, visa proporcionar maior familiaridade com o objeto pesquisado, tornando-o mais explícito ou possibilitando a construção de hipóteses (SILVA et al., 2005).

As técnicas selecionadas consistem em revisão bibliográfica para elaboração do referencial teórico e, para a coleta e análise das informações, optou-se pela blibliometria, a qual permite a identificação do número de trabalhos sobre determinado assunto e publicados em datas específicas, colaborando para a sistematização do conhecimento desenvolvido e para o diagnóstico de problemas futuros a serem investigados (CHUEKE et al., 2015; FERREIRA, 2002).

No campo da bibliometria, algumas leis (ou princípios) de comportamento do pesquisador podem ser observadas e aplicadas, individualmente ou em conjunto. Para o presente estudo, optou-se pela utilização da Lei de Zipf, formulada por George Kingsley Zipf na década de 40. De modo geral, define-se a Lei de Zipf como uma base matemática e linguística capaz de analisar a frequência da distribuição das palavras em um determinado texto, independentemente de seu caráter ser ou não científico, também conhecida como Lei do Mínimo Esforço (GUEDES et al., 2005).

Em um primeiro momento, foram buscados subsídios para a elaboração do referencial teórico através de livros impressos e digitais, além de produções científicas em bases eletrônicas de dados diversas, visando o reconhecimento do objeto de pesquisa, vislumbrando a sua compreensão de modo sistêmico. Em seguida, para a execução da bibliometria, delimitaram-se os critérios de aceitabilidade e exclusão, tanto dos periódicos quanto dos artigos selecionados. Optou-se pela busca de artigos indexados na base de dados Scientific Periodicals Electronic Library (SPELL), ferramenta de pesquisa nacional que permite o acesso integral a todos os conteúdos (Open Access). A escolha pela referida base deu-se em virtude do intuito de compreender a produção científica nacional acerca da temática, relevante para a Administração Pública brasileira, que ainda caminha a passos lentos em termos de desenvolvimento e evolução.

Para a pesquisa, utilizaram-se os termos 'Educação a distância' e 'Qualificação', apresentando-se, em um primeiro momento, os resultados gerais para, em etapa mais específica, proceder à análise dos artigos mais relevantes e aderentes à temática do presente estudo. O termo 'Educação a distância' foi selecionado para a pesquisa no contexto nacional, uma vez que a o termo 'e-learning', apesar de estar se consolidando como a nomenclatura atual da terceira geração desta modalidade educacional, ainda é pouco utilizada nas produções acadêmicas e científicas nacionais. 
Os critérios de aceitabilidade dos artigos escolhidos foram: período de publicação (janeiro de 2015 a dezembro de 2019) e convergência com a temática da Administração Pública, verificada em três etapas: primeiramente, verificou-se o título; em um segundo momento, procedeu-se à leitura do resumo e, em seguida, à leitura integral das produções científicas, buscando selecionar apenas aquelas que apresentassem relação direta com a qualificação do servidor público através da educação a distância. 0 destaque para o período mencionado (2015-2019) se deve ao fato de se desejar reconhecer o estado atual da produção acadêmica e científica na área sobre os temas pesquisados (FERREIRA, 2002).

\section{DISCUSSÃO TEÓRICA}

Nesta seção, contextualiza-se a aprendizagem organizacional a partir dos ensinamentos de Peter Senge (2013), trazidos à contemporaneidade e aplicados no contexto da Administração Pública. Em seguida, consonante à necessidade dos órgãos públicos demonstrarem-se como organizações que aprendem, abordase a educação a distância como ferramenta atual para a promoção da qualificação d servidor público, peçachave no processo da aprendizagem organizacional pública.

\section{Aprendizagem organizacional na administração pública}

Peter Senge, em sua obra "A Quinta Disciplina", delimitou cinco direções a serem seguidas pelas organizações que desejam tornarem-se learning organizations: pensamento sistêmico; domínio pessoal; modelos mentais; visão compartilhada e aprendizado em equipe. Sua obra foi atualizada, editada e republicada diversas vezes ao longo dos anos, buscando a aproximação com a realidade contemporânea. Conforme o pensamento sistêmico é preciso realizar conexões entre as ideias, compartilhando informações e responsabilidades. O domínio pessoal se refere à individualidade, ou seja, ao entusiasmo e compromisso de cada colaborador. Modelos mentais, por sua vez, dizem respeito ao processo de autorreflexão na busca pela generalização dos conhecimentos. A visão compartilhada define as particularidades, mas permite a socialização das visões originais, diversificando o ambiente de trabalho. Por fim, o aprendizado em equipe significa a consolidação de todo o conhecimento, a partir do momento em que os envolvidos compartilham as informações com o objetivo de enriquecer a cultura organizacional e auxiliar de maneira direta no alcance de seus objetivos (SENGE, 2013).

As organizações que aprendem, segundo Senge (2013), são possíveis a partir da percepção de que o aprendizado faz parte da natureza do homem e, deste modo, exploram sua própria capacidade de criar a aprender, de modo contínuo e coletivo. A aprendizagem organizacional é constante, não pode ser delimitada por objetivos específicos, pois o processo é permanente: cada indivíduo, ao aprender e se qualificar, reproduz seu conhecimento no âmbito organizacional, promovendo o aprendizado em conjunto.

Hansen et al. (2020) buscaram trazer as teorias de Peter Senge para a atualidade. Seu estudo não se limitou a avaliar a relevância original das cinco disciplinas, mas considerar a possibilidade de que elas possam possuir novos significados para as organizações contemporâneas. Neste contexto, os autores abordam a "inovação responsável" como uma premissa das organizações que aprendem na atualidade. A abordagem da 
inovação responsável diz respeito às organizações de pesquisa e inovação, afirmando que as mesmas devem agir com absoluta responsabilidade, avaliando as consequências sociais desses atos. No entanto, é possível transcender este conhecimento para as demais organizações, considerando que as cinco disciplinas de Peter Senge se reconstroem na medida em que ocorrem as transformações sociais, evoluindo para comportamentos organizacionais cada vez mais responsáveis com a coletividade.

Na Administração Pública, as transformações paradigmáticas transpassadas ao longo das últimas décadas se fizeram necessárias a partir do momento em que se perceberam as demandas da sociedade moderna, através da formação de novas configurações sociais e governamentais e ensejando reformas na maneira de pensar e fazer o serviço público. Inicialmente patrimonialista, o setor público atravessou fases como a burocracia, o gerencialismo e o paradigma social; estas transformações provocaram, no transcorrer da história, rejeições e desconfianças, reservas e temores, pois questionaram e questionam verdades, desmontam e reconstroem conceitos (TEPERINO et al., 2006).

Cumpre ressaltar que as ações governamentais têm sinalizado para a necessidade de promoção da aprendizagem organizacional, embora a produção científica e os estudos de campo na área ainda sejam escassos. Conforme Bertolin et al. (2013), esta situação evidencia "oportunidades para o desenvolvimento de pesquisas nesse setor, já que este tem especificidades diferentes do setor privado, em que grande parte da produção acadêmica e empírica tem se baseado". De fato, há que se ressaltarem as divergências entre as organizações públicas e privadas, especialmente quanto a seus objetivos: na administração privada, fala-se em lucros e satisfação de demandas individuais; na esfera pública, não há que se falar em outro objetivo que não o bem comum da coletividade.

Acerca da capacidade de aprender relacionada às organizações públicas, McCurdy (2011) afirma ser este um desafio com profundas implicações. Para o autor, as mudanças políticas constantes acarretam a ruptura de ações e, consequentemente, resistência à continuidade destas, tornando o aprendizado e a mudança institucional muito difícil de ser alcançado. Para Bertolin et al. (2013), os espaços de aprendizagem podem ser implementados no contexto público desde que considerem o compartilhamento do conhecimento através de uma colaboração reflexiva, buscando modificar o excesso de formalismo que ainda impera na Administração Pública contemporânea. Gerir o conhecimento nas organizações públicas requer a implementação de uma cultura do conhecimento, substituindo a ênfase em ferramentas técnicas pelo destaque às pessoas e sua capacidade de aprendizagem (LUCCA et al., 2018).

Teperino et al. (2006) criticam o tradicionalismo e a burocratização ainda presentes na Administração Pública, ressaltando-se que a resistência a mudanças se origina de questões históricas. Para McCurdy (2011), gerentes seniores, por exemplo, não compreendem as transformações sociais (principalmente as tecnológicas), pois chegaram ao poder em um ambiente antigo de negócios. Trazendo está acepção para a realidade da Administração Pública, é possível notar a existência de muitos gestores públicos nesta mesma condição: o início de suas gestões se deu em décadas anteriores, marcadas pela burocracia. As mudanças cada vez mais constantes ainda não fazem parte de suas agendas, embora já possam ser identificadas em estudos mais recentes. Nesta seara, Moynihan et al. (2009) afirmam haver incompatibilidade entre 
conhecimento e autoridade, considerando que um gestor mais antigo na função pode não possuir a mesma motivação que um servidor no início de sua carreira e, por sua vez, o início da carreira pública não confere a autoridade necessária para a promoção de transformações mais complexas.

As organizações (em especial as públicas) que não se propõem a incentivar seu próprio aprendizado e de seus colaboradores perdem potenciais oportunidades, tornando seus processos cada vez mais ineficazes (MOYNIHAN et al., 2009) e, com isso, proporcionando críticas ao setor público como um todo, promovendo inclusive a desmotivação do servidor (TEPERINO et al., 2006). Deve-se, portanto, suprimir o hiato entre conhecimentos, habilidades e atitudes necessários ao desempenho eficaz dos servidores, tendo em vista os conceitos de competências na área de gestão de pessoas e seus processos para a promoção da aprendizagem organizacional (MARTINS et al., 2019). Neste contexto, a qualificação individual (e, consequentemente, o aprendizado das organizações públicas) demonstra-se como uma expressiva oportunidade de melhoria no pensar e fazer Administração Pública. Acompanhando-se as transformações tecnológicas e as evoluções sociais, destaca-se a educação a distância como uma ferramenta promissora para a qualificação profissional dos servidores públicos.

\section{Educação a distância para a qualificação do servidor público}

'Educação a distância', 'ensino a distância' e 'e-learning' são faces de um mesmo conceito: o uso de tecnologias para a promoção do aprendizado à distância. Para Martins, et al. (2019), trata-se de "uma modalidade de EAD, dada em função do uso de tecnologias da Internet para disponibilizar as mídias de ensino e estabelecer a interação entre alunos e professores". O termo e-learning refere-se à terceira geração do aprendizado à distância. A primeira geração ocorreu com o ensino por correspondência; a segunda, com a promoção de vídeo aulas ou áudios difundidos por instituições de ensino diversas; a terceira geração caracteriza-se pelo uso da internet, através de ambientes virtuais, redes sociais, recursos multimídia diversos, entre outros (PONTES et al., 2017). A EAD promove a interação, "possível mediante as tecnologias de comunicação cada vez mais fluentes e eficazes" e a flexibilização de conteúdo, prazos, ritmo de aprendizado (SILVA et al., 2015). Nos últimos anos, esta modalidade de ensino ganhou adeptos nas diversas áreas da sociedade, sendo uma ferramenta de grande valia para as organizações públicas e privadas.

A educação no campo da Administração Pública envolve discussões diversas. Conforme Denhardt (2001), um dos maiores debates diz respeito à relação efetiva entre teoria e prática, principalmente no contexto acadêmico. Para o autor, a formação acadêmica em Administração Pública não foi desenvolvida para aproximar o aluno, de fato, das controvérsias sociais. Por esta razão, ainda que o servidor público possua formação na área, a qualidade de suas ações profissionais depende da correlação entre as teorias aprendidas e a práxis do serviço público. Os administradores públicos necessitam, portanto, desenvolver habilidades capazes de promover transformações e mudanças no setor público e, deste modo, devem possuir embasamentos teóricos, acadêmicos, profissionais, sociais e psicológicos para tanto (DENHARDT, 2001).

De acordo com Ranzini et al. (2017) as ações de qualificação destes profissionais geram resultados somente se estiverem "efetivamente vinculadas às demandas identificadas, capazes de diminuir as lacunas 
de qualificação e promover melhorias no desempenho individual e organizacional". Compreende-se a qualificação profissional do servidor público, portanto, como uma premissa para a consequente melhoria da eficiência na prestação de serviços e ações voltadas à coletividade.

A profissionalização do servidor público e, consequentemente, das organizações públicas, é uma tendência atual originada na reforma estatal e que tem despertado a necessidade de se pensar novos arranjos institucionais, avançando cada vez mais nas relações adequadas entre Administração Pública e sociedade. Ressalta-se, entretanto, que "a configuração da administração pública ainda se detém na visão baseada em custos e muito menos em oportunidades" (BERTOLIN et al., 2013).

Nas últimas décadas, surgiram as Escolas de Governo, ou Escolas de Gestão Pública, Escolas do Serviço Público, dentre outras tantas denominações. Estas instituições foram criadas por diversos entes federativos e nas três esferas governamentais, buscando atender à demanda de qualificação dos servidores (RANZINI et al., 2017). Importante destacar que diversos entes federativos (principalmente municípios) não criaram suas próprias escolas, utilizando-se, conforme a demanda, de escolas de entes superiores (estatais e federal). Souza et al. (2019) atentam para o acesso aos conteúdos das Escolas de Governo também pelos cidadãos, com vistas ao estímulo do exercício do controle social através da compreensão e qualificação em gestão pública.

O uso da EAD promovido pelas Escolas de Governo ou outras instituições confere benefícios relevantes e aplicáveis à Administração Pública, tais como baixo custo, envolvimento de um número maior de indivíduos, universalidade e acessibilidade aos conteúdos, estímulo ao compartilhamento das informações entre alunos e colegas de trabalho, expansão do conhecimento e consequente melhoria nos processos, entre outros (MARTINS et al., 2019; PONTES et al., 2017). Depreende-se, portanto, que esta modalidade educacional proporciona diversos benefícios no âmbito público, em especial por promover maior flexibilidade e menor custo quanto comparado à qualificação presencial, indo ao encontro das premissas da eficiência da Administração Pública, cada vez mais carente de recursos.

Pontes et al. (2017) corroboram com a relevância da qualificação do servidor público, uma vez que o mesmo contribui para a Administração Pública na medida em que busca seu crescimento pessoal e investe em sua própria carreira profissional. Deste modo, a valorização do capital humano existente e a criação de sinergias nas forças de trabalho promovem o compartilhamento dos interesses e a busca por orientações capazes de elevar a responsabilidade dos servidores para com o exercício de suas funções e, consequentemente, para com a própria Administração Pública. Neste sentido, a EAD torna-se uma ferramenta de grande valia, capacitando servidores e promovendo o aprendizado organizacional no setor público.

Conforme Martins et al. (2019), a gestão de pessoas no contexto público "vem sendo redimensionada em busca de desenvolver seus servidores, em prol de um desempenho de suas competências institucionais e individuais frente à formulação e implementação de políticas públicas". Deste modo, buscar formas de incentivo e apoio, além de oferecer oportunidades de qualificação é uma premissa da Administração Pública, contribuindo para o aprimoramento das competências organizacionais e, portanto, promovendo o 
aprendizado constante (MARTINS et al., 2019). Teperino et al. (2006) atentam, ainda, para a necessidade de sensibilização dos servidores e gestores públicos em relação ao aperfeiçoamento constante exigido para as atribuições profissionais.

Perceber o Estado sob novas perspectivas é uma demanda atual da sociedade, tendo em vista que os indivíduos estão se tornando cidadãos cada vez mais conscientes acerca do papel que deve ser desempenhado pela Administração Pública. Desta forma, a promoção da qualificação e do desenvolvimento de habilidades e competências dos servidores públicos (principalmente através de ferramentas tecnológicas), torna-se uma premissa para que o aparato estatal possa desenvolver suas ações de maneira proveitosa e em conformidade com o seu maior objetivo, que é o bem da coletividade.

\section{Descrição e análise dos resultados}

Mediante aplicação da metodologia anteriormente exposta, os primeiros resultados da busca pelos termos “Educação a distância” e “Qualificação” retornaram os indicativos apresentados no Quadro 1.

Quadro 1: Resultados iniciais da busca pelos termos-chave (continua).

\begin{tabular}{|l|l|l|l|}
\hline \multicolumn{1}{|c|}{ Termos-chave } & \multicolumn{1}{c|}{$\begin{array}{c}\text { Total } \\
\text { Artigos }\end{array}$} & Artigos 2015-2019 & \multicolumn{1}{c|}{$\begin{array}{c}\text { Total } \\
\text { Periódicos }\end{array}$} \\
\hline Educação a distância & 51 & 28 & 34 \\
\hline Qualificação & 21 & 17 & 19 \\
\hline Total geral & $\mathbf{7 2}$ & $\mathbf{4 5}$ & $\mathbf{5 3}$ \\
\hline
\end{tabular}

Em uma análise inicial, é possível perceber que do total de artigos publicados na base de dados Spell encontrados através da busca do termo "Educação a distância", 55\% foram indexados até 2019. Da mesma forma, observa-se que, a partir da pesquisa da palavra-chave "Qualificação", 81\% do total de artigos foram publicados no mesmo período. Estes resultados são apresentados de maneira mais detalhada no gráfico a seguir.

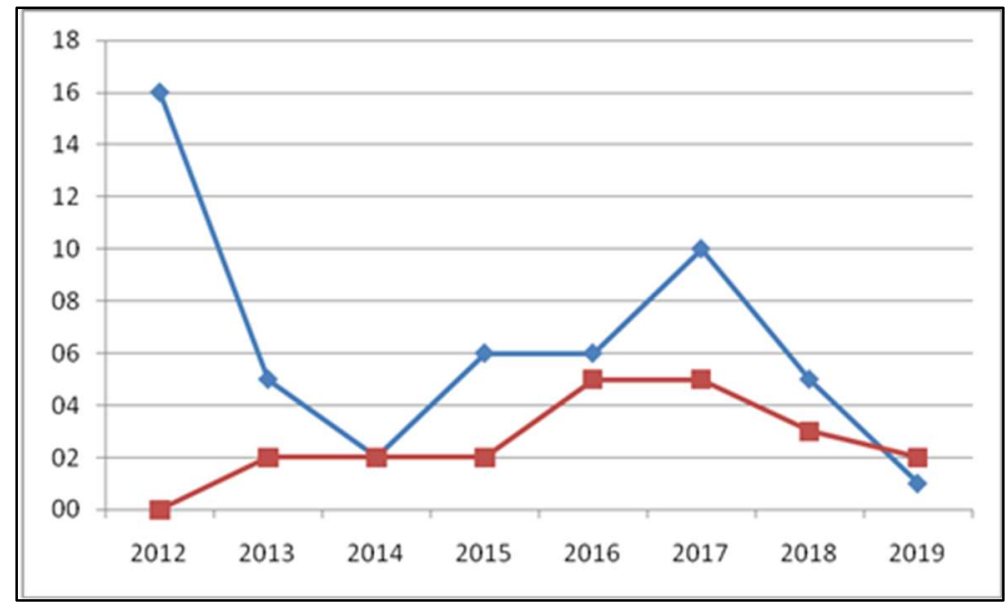

Gráfico 1: Comparativo entre número de artigos.

A linha superior refere-se aos totais de artigos publicados, por ano, aderentes à temática da educação a distância, enquanto a linha inferior diz respeito aos totais referente à temática qualificação. Percebe-se que, em 2012, houve um número significativamente maior de artigos relacionados ao tema da EAD, situação que se repete (ainda que de forma mais moderada) em 2017. Quanto à linha inferior, aufere-se certa 
constância nas produções a partir de 2013.

Considerando o propósito do estudo, de discorrer especificamente as produções nacionais do período compreendido entre janeiro de 2015 e dezembro de 2019, procedeu-se à análise de cada um dos artigos encontrados, mediante a observação de três etapas: primeiramente, verificou-se o título; em um segundo momento, procedeu-se à leitura do resumo e, em seguida, à leitura integral das produções científicas, buscando selecionar apenas aquelas que apresentassem relação direta com a qualificação do servidor público através da educação a distância. Os resultados encontrados após cada uma das etapas encontram-se dispostos no Quadro 2.

Quadro 2: Artigos selecionados (2015-2019).

\begin{tabular}{|l|l|l|}
\hline \multicolumn{1}{|c|}{ Etapa } & \multicolumn{1}{|c|}{ Termos-chave } & Artigos \\
\hline \multirow{2}{*}{ 1) Verificação do título } & Educação a distância & 06 \\
\cline { 2 - 3 } 2) Leitura do resumo & Qualificação & 03 \\
\hline \multirow{2}{*}{ 3) Leitura integral } & Educação a distância & 03 \\
\cline { 2 - 3 } & Qualificação & 02 \\
\cline { 2 - 3 } & Educação a distância & 03 \\
\cline { 2 - 3 }
\end{tabular}

Após a leitura em profundidade dos artigos pesquisados, do total geral de artigos encontrados (45 no período estipulado), foram selecionados, ao final, 4 (correspondente a $9 \%$ da amostra), a saber no quadro 3.

Quadro 3: Artigos selecionados.

\begin{tabular}{|l|l|l|}
\hline № & Ano & Artigo \\
\hline 1 & 2016 & $\begin{array}{l}\text { CAMPOS, K. A.; SANTOS, F. M.. A educação a distância no âmbito da educação permanente em saúde do Sistema } \\
\text { Único de Saúde (SUS). Revista do Serviço Público, v.67, n.4. }\end{array}$ \\
\hline 2 & 2017 & $\begin{array}{l}\text { DURAN, D.. A educação a distância no processo de formação continuada da administração pública: as contribuições } \\
\text { da Revista do Serviço Público. Revista do Serviço Público, v.68, n.3. }\end{array}$ \\
\hline 3 & 2015 & $\begin{array}{l}\text { BUCHELE, G. T.; SCHMITZ, L. C.; DANDOLIN, G. A.. Um plano de gerenciamento de projetos no contexto da educação } \\
\text { a distância no ambiente público. Revista de Gestão e Projetos, v.6, n.2, p.100-114. }\end{array}$ \\
\hline 4 & 2015 & $\begin{array}{l}\text { FERREIRA, L. G.; ZIVIANI, F.; OLIVEIRA, J. L. R.; MEDEIROS, M. L.. Influências dos incentivos à qualificação dos } \\
\text { servidores técnico-administrativos da Universidade Federal de São João Del Rei. Teoria e Prática em Administração, } \\
\text { v.5, n.1, p.183-203. }\end{array}$ \\
\hline
\end{tabular}

A primeira percepção possível consiste no fato de que, no período analisado (2015-2019), apenas 9\% possui aderência à temática do presente estudo. Desta forma, verifica-se um quantitativo que demonstra um campo que carece de aprofundamento, no tocante aos periódicos indexados na base de dados analisada. Os quatro artigos selecionados são analisados em seguida, comprovando sua relevância para a construção do presente estudo.

O primeiro artigo corresponde aos estudos de Campos et al. (2016). Os autores trazem uma reflexão acerca da educação permanente como uma política pública de saúde, sendo relevante para a qualificação dos profissionais do Sistema Único de Saúde (SUS) e consequente melhoria nos processos de trabalho. No campo da EAD, destaca-se a inserção do uso de tecnologias para o ensino em saúde a partir de 2006, com o Programa Telessaúde Brasil, através do qual se realizavam videoconferências entre os participantes. Em 2010, com a criação da Universidade Aberta do SUS (UNASUS), buscou-se o fomento e apoio à disseminação das tecnologias para ampliação do alcance das atividades educativas e profissionalizantes.

Conclui-se que "a educação a distância demonstra agregar características que a qualificam como 
estratégia elegível na implementação de eventos de formação na área da saúde pública" (CAMPOS et al., 2016), devendo ser devidamente planejada e compreender as possíveis resistências apresentadas durante o processo de qualificação profissional. $O$ destaque deste artigo deve-se à sua abordagem profissional em uma área específica (saúde pública no Brasil), evidenciando a profissionalização dos servidores colaboradores do SUS e mencionando a relevância da formação continuada nesta área, tão significativa para a sociedade brasileira.

As contribuições da Revista do Serviço Público acerca da EAD como instrumento de formação continuada na Administração Pública foram o objeto de estudo de Duran (2017). A autora dedicou-se à pesquisa das publicações no referido periódico, aderentes à temática da formação continuada, no período de 1989 a 2016. Verificou-se um total de $4 \%$ do total de títulos publicados que abordaram a temática destacada. Em se tratando desta modalidade de educação, Duran (2017) encontrou 7 textos no período pesquisado, os quais evidenciaram a EAD como estratégia promissora e ainda pouco utilizada na Administração Pública, capaz de promover a formação continuada dos servidores públicos.

O artigo de Duran (2017) foi selecionado em virtude de realizar um apanhado bibliométrico acerca da temática deste estudo, em período anterior ao destacado no presente; logo, trata-se de estudos complementares. Depreende-se, das informações coletadas em ambos os estudos, que a produção nacional acerca da EAD enquanto ferramenta de qualificação do servidor público ainda ocupa um espaço relativamente pequeno no rol total de produções científicas e acadêmicas no Brasil.

Os estudos de Buchele et al. (2015) foram selecionados em virtude de apresentarem aspectos pontuais acerca do planejamento da qualificação de servidores através da educação a distância como uma necessidade essencial para a redução de custos e a prestação de serviços públicos de qualidade. O foco deste estudo consistiu em relatar o desenvolvimento de um plano para gerenciamento do projeto de criação de um Núcleo de Capacitação a Distância para servidores do Estado de Santa Catarina, cujos resultados apontaram aspectos positivos na implantação do projeto, integrando as capacitações de todos os órgãos estatais e reduzindo os custos destas ações, gerando possibilidade de investimentos em outras áreas.

De maneira geral, este artigo foi escolhido por trazer um viés mais técnico para a gestão da Administração Pública, revelando a necessidade de se lançar um olhar sistêmico e de planejamento sobre os processos internos dos órgãos públicos. Em se tratando do aprendizado dos servidores públicos, os autores afirmam que "o cenário atual das organizações apresenta uma necessidade de aprendizagem contínua para suprir as expectativas dos usuários quanto à qualidade dos serviços prestados" (BUCHELE et al., 2015).

O quarto artigo selecionado corresponde a um estudo da influência de incentivos da Lei Federal no 11.091/2005 à qualificação de servidores públicos de uma Universidade Federal. A referida lei instituiu o Plano de Carreira dos Cargos Técnico-Administrativos em Educação (PCCTAE) e, segundo as informações coletadas pelo estudo, percebe-se que a procura por qualificação aumentou significativamente desde a instituição deste Plano de Carreira (FERREIRA et al., 2015). O estudo se destaca, portanto, por produzir subsídios capazes de serem replicados nos órgãos públicos de todas as esferas, instituindo-se planos de carreiras que incentivem os servidores públicos à profissionalização. 
Diante da análise individual dos artigos, o Quadro 4 apresenta um compilado destas considerações, além de destacar as metodologias utilizadas e aplicando a Lei de Zipf nos termos-chave pesquisados, ver quadro 4.

Quadro 4: Análise resumida dos artigos.

\begin{tabular}{|c|l|l|l|}
\hline No & Metodologia & Tema principal e Conclusões & Repetições \\
\hline 1 & $\begin{array}{l}\text { Qualitativa } \\
\text { Descritiva, } \\
\text { Bibliográfica. }\end{array}$ & $\begin{array}{l}\text { Importância da EAD na formação em saúde pública; necessidade } \\
\text { de planejamento e compreensão das resistências. }\end{array}$ & $\begin{array}{l}\text { Educação a distância / EAD: } \\
73 \\
\text { Qualificação: } 04\end{array}$ \\
\hline 2 & $\begin{array}{l}\text { Qualitativa } \\
\text { Descritiva, } \\
\text { Bibliográfica. }\end{array}$ & $\begin{array}{l}\text { Contribuições da Revista do Serviço Público; relevância da EAD } \\
\text { para a formação continuada e necessidade de qualificação destes } \\
\text { processos de ensino. }\end{array}$ & $\begin{array}{l}\text { Educação a distância / EAD: } \\
53 \\
\text { Qualificação: 02 }\end{array}$ \\
\hline 3 & $\begin{array}{l}\text { Qualitativa, } \\
\text { Documental, } \\
\text { Estudo de campo. }\end{array}$ & $\begin{array}{l}\text { Criação de um plano para gerenciamento do projeto de criação do } \\
\text { núcleo de Capacitação a Distância para os servidores Estaduais; } \\
\text { públicos. }\end{array}$ & $\begin{array}{l}\text { Educação a distância / EAD: } \\
04 \\
\text { Qualificação: } 02\end{array}$ \\
\hline 4 & $\begin{array}{l}\text { Quantitativa, } \\
\text { Descritiva, } \\
\text { Questionário. }\end{array}$ & $\begin{array}{l}\text { Plano de Carreira dos Cargos Técnico-Administrativos em } \\
\text { Educação (PCCTAE); relevância para o incentivo à qualificação dos } \\
\text { servidores. }\end{array}$ & $\begin{array}{l}\text { Educação a distância / EAD: } \\
00 \\
\text { Qualificação: 73 }\end{array}$ \\
\hline
\end{tabular}

As metodologias empregadas pelos artigos selecionadas evidenciam a utilização tanto de abordagem qualitativa quanto quantitativa, depreendendo-se, portanto, a possibilidade de utilização de diversas técnicas para a realização de estudos acerca desta temática. Ambas as abordagens se complementam, pois, da mesma forma em que a visão sistêmica, possível através do estudo de caso, permite a compreensão mais abrangente da qualificação do servidor público através da educação a distância, o uso de metodologias quantitativas permite a coleta de dados mais específicos, proporcionando a efetiva integração entre teoria e prática.

Em se tratando dos termos-chave pesquisados, pode-se observar que o primeiro artigo mencionado, de Campos et al. (2016), possui o maior número de repetições do termo "Educação a distância", enquanto o termo “Qualificação" surge mais vezes no artigo de Ferreira et al. (2015). Em estudos futuros, pondera-se a necessidade de realização de análise bibliométrica mais aprofundada, segundo os princípios mencionados por G. K. Zipf, em todos os artigos pesquisados, inicialmente, a partir dos termos-chave determinados.

\section{CONCLUSÕES}

O artigo buscou identificar a relevância da qualificação profissional do servidor público através do uso de tecnologias e, em especial, da educação a distância. O referencial teórico coletado possibilitou um apanhado científico adequado e capaz de consolidar está relevância, sendo possível evidenciar, inclusive, que a qualificação do servidor público implica na promoção da aprendizagem organizacional da Administração Pública, trazendo inúmeros benefícios ao setor público e, consequentemente, aos cidadãos, através de serviços públicos prestados com qualidade e eficiência.

Os resultados encontrados a partir da pesquisa bibliométrica na base de dados SPELL evidenciaram, inicialmente, um total de 53 artigos relacionados aos termos-chave pesquisados. No entanto, após a análise dos mesmos em observância às três etapas mencionadas na metodologia, apenas 4 artigos foram selecionados por atenderem plenamente à temática deste estudo. Nota-se, portanto, um número reduzido 
de produções científicas aderentes à temática no contexto total de publicações, indicando um campo fértil para o desenvolvimento de pesquisas e rompimento de paradigmas teóricos.

Referente à delimitação da base de dados SPELL, importa ressaltar que o objetivo deste estudo consiste em identificar a produção científica nacional e, desta forma, optou-se pela base mencionada. Diante das informações coletadas e artigos analisados, compreende-se que a Administração Pública ainda é tema recente de estudos no país, sendo a temática deste artigo um assunto que demonstra ainda menos produções cientificas nacionais indexadas na SPELL.

Com base no estudo realizado, sugerem-se as seguintes proposições: a) a disponibilização de cursos a distância nas plataformas digitais de escolas de governo brasileiras evidencia outra possibilidade de estudos futuros, identificando estas plataformas e categorizando-as de acordo com o contexto em que estão inseridas (político, governamental, empresarial); b) identificar, dentro das plataformas digitais de escolas de governo as características dos cursos online ofertados, público-alvo, carga-horária, entre outros atributos relevantes à determinação de categorias de análise possíveis de implementação; c) realizar novo estudo, tendo por escopo outra (s) base (s) de dados, vislumbrando as produções científicas em nível mundial; d) realizar estudo específico a partir dos princípios metodológicos da bibliométrica, tais como as leis de Zipf, Lotke e outras; e) contextualizar as realidades dos órgãos da Administração Pública das três esferas, buscando a realização de estudos específicos no âmbito municipal, estadual e federal.

Diante destas proposições e, ainda, considerando as informações coletadas, compreende-se que a EAD é uma ferramenta atual, fruto da evolução das tecnologias, cuja utilização pela esfera pública possibilita a qualificação de seus servidores, buscando a profissionalização e a promoção da aprendizagem organizacional dos órgãos públicos. As demandas sociais são cada vez mais exigentes e, neste contexto, à Administração Pública cabe estimular o acesso à instrução de seus colaboradores, visando a oferta de serviços públicos de qualidade, indo ao encontro dos interesses coletivos da sociedade.

\section{REFERÊNCIAS}

ARAÚJO, C. A.. Bibliometria: evolução histórica e questões atuais. Revista em Questão, v.1, n.12, p.11-32, 2006.

BERTOLIN, R. V.; ZWICK, E.; BRITO, M. J.. Aprendizagem organizacional socioprática no serviço público: um estudo de caso interpretativo. Revista de Administração Pública, v.47, n.2, p.493-513, 2013.

BUCHELE, G. T.; SCHMITZ, L. C. DANDOLIN, G. A.. Um plano de gerenciamento de projetos no contexto da educação a distância no ambiente público. Revista de Gestão e Projetos, v.6, n.2, p.100-114, 2015.

CAMPOS, K., SANTOS, F.. A educação a distância no âmbito da educação permanente em saúde do Sistema Único de Saúde (SUS). Revista do Serviço Público, v.67, n.4, p.603626, 2016.

CHUEKE, G. V.; AMATUCCI, M.. O que é bibliometria? Uma introdução ao fórum. Internext: Revista Eletrônica de Negócios Internacionais, v.10, n.2, p.1-5, 2015. DOI: http://dx.doi.org/10.18568/1980-4865.1021-5
DENHARDT, R. B.. The big questions of Public Administration Education. Public Administration Review, v.61, n.5, p.526534, 2001. DOI: http://doi.org/10.1111/0033-3352.00125

DURAN, D.. A educação a distância no processo de formação continuada da administração pública: as contribuições da Revista do Serviço Público. Revista do Serviço Público, v.68, n.3, p.705-736, 2017.

FERREIRA, L. G.; ZIVIANI, F.; OLIVEIRA, J. L. R.; MEDEIROS, M. L.. Influências dos incentivos à qualificação dos servidores técnico-administrativos da Universidade Federal de São João Del Rei. Teoria e Prática em Administração, v.5, n.1, p.183203, 2015.

FERREIRA, N. S. A.. As pesquisas denominadas 'Estado da Arte'. Educação \& Sociedade, v.23, n.79, p.257-272, 2002. DOI: https://doi.org/10.1590/S0101-73302002000300013

GUEDES, V. L. S.; BORSCHIVER, S.. Bibliometria: uma ferramenta estatística para a gestão da informação e do 
conhecimento em sistemas de informação, de comunicação e de avaliação científica e tecnológica. In: ENCONTRO NACIONAL DE CIÊNCIA DA INFORMAÇÃO, 6. Anais: Salvador, 2005. p.1-18.

HANSEN, J. O.; JENSEN, A.; NGUYEN, N.. The responsible learning organization: Can Senge (1990) teach organizations how to become responsible innovators? The Learning Organization, v.27, n.1, p.65-74, 2020. DOI: https://doi.org/10.1108/TLO-11-2019-0164

LUCCA, D. M.; FIALHO, F. A. P.; VITORINO, E. V.. Competência em informação e aprendizagem ao longo da vida nas organizações que aprendem. Revista Ibero-americana de Ciência da Informação, v.11, n 3, p.590-608, 2018. DOI: https://doi.org/10.26512/rici.v11.n3.2018.10373

MARTINS, A. R.; PONTES, W. L.; COUTINHO, A. R. S.. Competências de servidores públicos através do e-learning: um estudo de caso no ensino. Revista Observatório, v.5, n.3, p.50-84, 2019. DOI: https://doi.org/10.20873/uft.24474266.2019v5n3p50

MINAYO, M. C. S.. Ciência, Técnica e Arte: o desafio da pesquisa social. In: MINAYO, M. C. S.. Pesquisa social: Teoria, método e criatividade. 21 ed. Petrópolis: Vozes, 2002. p.9-29.

MCCURDY, H. E.. Can Government Organizations learns and change? Public Administration Review, p.316-319, 2011. DOI: https://doi.org/10.1111/j.1540-6210.2011.02348.x

MOYNIHAN, D. P.; LANDUYT, N.. How do Public Organizations learn? Bridging cultural and sctructural perspectives. Public Administration Review, v.69, p.10971105, 2009. DOI: https://doi.org/10.1111/j.15406210.2009.02067.x

PONTES, W. L.; MARTINS, A. R.; COUTINHO, A. R.; GARRETO,
M. S. E.. A Qualificação por meio do E-learning para o Desenvolvimento de Competências de Servidores Públicos de uma Instituição Federal de Ensino Superior. In: ENCONTRO DA ASSOCIAÇÃO NACIONAL DE PÓS GRADUAÇÃO E PESQUISA EM ADMINISTRAÇÃO. Anais: São Paulo, 2017.

RANZINI, M. S.; BRYAN, N. A. P.. Capacitação e formação para o setor público e os modelos de escola de governo no Brasil. Revista do Serviço Público, v.68, n.2, p.417-438, 2017.

SENGE, P.. A quinta disciplina: a arte e a prática da organização que aprende. 29 ed. Rio de Janeiro: Best Seller, 2013.

SILVA, M. P. D.; MELO, M. C. O. L.; MUYLDER, C. F.. Educação a distância em foco: um estudo sobre a produção científica brasileira. Revista de Administração Mackenzie, v.16, n.4, p.202-230, 2015. DOI: https://doi.org/10.1590/167869712015/administracao.v16n4p202-230

SILVA, E. L.; MENEZES, E. M.. Metodologia da pesquisa e elaboração da dissertação. 4 ed. Florianópolis: UFSC, 2005.

SOUZA, F. V.; MOTOKI, F. Y. S.. Antecedentes e os Resultados no E-Learning Corporativo Público. In: ENCONTRO DA ASSOCIAÇÃO NACIONAL DE PÓS-GRADUAÇÃO E PESQUISA EM ADMINISTRAÇÃO. Anais: Fortaleza, 2019.

TEPERINO, A. S.; GUEFI, A. C.; KIPNIS, B.; LONGO, C.; LOPES, C. M. B.; LIMA, E. D. B.; CORDÃO, F. A.; CHAVES FILHO, H.; ALMEIDA, J. N. C.; MACHADO, M. S.; LARROYED, M.; ALMEIDA, M. A.; SANTOS, M. E. F.; JOSHINO, P.; CARBONE, P. P.; SILVA, S. P. C.; LEITE, S. D.; HOROVITS, S. A. B.; NASCIMENTO, T. P. C.. Educação a distância em organizações públicas: Mesa-redonda de pesquisa-ação. Brasília: ENAP, 2006.

A CBPC - Companhia Brasileira de Produção Científica (CNPJ: 11.221.422/0001-03) detém os direitos materiais desta publicação. Os direitos referem-se à publicação do trabalho em qualquer parte do mundo, incluindo os direitos às renovações, expansões e disseminações da contribuição, bem como outros direitos subsidiários. Todos os trabalhos publicados eletronicamente poderão posteriormente ser publicados em coletâneas impressas sob coordenação da Sustenere Publishing, da Companhia Brasileira de Produção Científica e seus parceiros autorizados. Os (as) autores (as) preservam os direitos autorais, mas não têm permissão para a publicação da contribuição em outro meio, impresso ou digital, em português ou em tradução. 